\title{
The impact of smoke-free legislation on reducing exposure to secondhand smoke: differences across gender and socioeconomic groups
}

\author{
Yi-Wen Tsai, ${ }^{1}$ Li-Chuan Chang, ${ }^{1}$ Hai-Yen Sung, ${ }^{2}$ Teh-wei Hu, ${ }^{3}$ Shu-Ti Chiou ${ }^{4,5}$
}

${ }^{1}$ Institute of Health and Welfare Policy, National YangMing University, Taipei, Taiwan, Republic of China ${ }^{2}$ Institute for Health \& Aging, University of California, San Francisco, California, USA ${ }^{3}$ School of Public Health, University of California, Berkeley, California, USA ${ }^{4}$ Institution of Public Health \& Department of Public Health, School of Medicine, National Yang-Ming University, Taipei, Taiwan, Republic of China ${ }^{5}$ Health Promotion Administration, Ministry of Health and Welfare, New Taipei City, Taiwan, Republic of China

\section{Correspondence to} Dr Shu-Ti Chiou, School of Medicine, National Yang-Ming University; Health Promotion Administration, Ministry of Health and Welfare, New Taipei City, Taiwan, Republic of China; Changqing St, Xinzhuang District, New Taipei City, Tiawn 242, Republic of China; stchiou@hpa.gov.tw

Received 20 February 2013 Accepted 8 July 2013 Published Online First 6 September 2013

\section{ABSTRACT \\ Background On 11 January 2009, Taiwan expanded its smoke-free legislation to all indoor public places and workplaces. This study examined the impact of this policy on secondhand smoke (SHS) exposure in adult non-smokers, across gender and socioeconomic status groups (SES).}

Methods An annual sample of about 13 000-14 000 non-smokers was drawn from cross-sectional nationwide data of Taiwan Adult Tobacco Behavior Surveys during 2005-2011. Logistic regressions were used to analyse the aggregate data to estimate the association between the 2009 smoke-free legislation and SHS exposures in homes and workplaces. Interaction terms were used to examine the impact of the 2009 smoke-free policy on reducing differences in SHS exposure across gender, education and income groups.

Results The 2009 policy reduced the odds of SHS exposure in homes in 2009 (OR=0.76, 95\% Cl 0.68 to 0.84 ) and in workplaces (year 2009: $O R=0.49,95 \% \mathrm{Cl}$ 0.39 to 0.62 ; year 2010 : $O R=0.79,95 \% \mathrm{Cl} 0.66$ to 0.95). The model with interaction terms showed that men were more likely than women to be exposed to workplace SHS (OR=2.02, 95\% Cl 1.80 to 2.27) but were less likely to be exposed to home SHS $(\mathrm{OR}=0.79$, $95 \% \mathrm{Cl} 0.73$ to 0.86$)$. SHS exposure in homes was significantly related to lower socioeconomic status, but the 2009 smoke-free policy reduced the difference in SHS exposure across education levels.

Conclusions The 2009 smoke-free policy reduced the SHS exposure for non-smokers. However, this impact on home SHS did not persist after 2009, and the effect of protection was unequal across gender and SES groups. Thus, further enforcement of smoking restrictions would be needed to reduce the risk of SHS exposure and improve protection against SHS risk among parts of the population with lower socioeconomic status.

\section{INTRODUCTION}

To reduce health harm from tobacco use, the Taiwan government implemented the Tobacco Hazards Prevention Act Amendment in January 2009 by enforcing several tobacco control measures. The most important measures included: (1) extending smoke-free areas to almost all enclosed workplaces and public places, (2) placing graphic warning labels on cigarette packs and (3) doubling tobacco taxes to NT\$20 (US\$0.66) per pack from June, 2009. ${ }^{1}$ The smoke-free policy was the focus of the tobacco control policy intervention. The Taiwan government held large-scale media campaigns, community education programmes and educational conferences to raise awareness, and also ensured that workplaces and public places posted no-smoking signs at all entrances. A small-scale survey in March 2009 reported a significant decrease in exposure to workplace secondhand smoke (SHS). ${ }^{1}$ No further studies have been conducted to examine the long-term effects of this expanded smoke-free legislation in Taiwan. Furthermore, no studies have examined whether the impact of the policy differed among subpopulation groups.

One suggested negative repercussion of smokefree policies was the 'displacement' or 'last refuge' hypothesis-smoking bans in public places would increase smoking in homes and thus increase the SHS exposure of non-smoking family members, particularly women and children. ${ }^{2-5}$ However, the 'social diffusion' hypothesis instead suggests that more restrictive smoking rules increase voluntary smoking restrictions in homes. ${ }^{6} 7$ Smoke-free legislation in Scotland and England was found to reduce SHS exposure among young people, including children whose parents adopted smoke-free policies at home. ${ }^{8} 9$

Another emerging issue involves the inequality aspect of the smoke-free policy, focusing on its impacts on less powerful subpopulations, particularly women of low socioeconomic status. ${ }^{10}{ }^{11}$ In California, low-income women were found to be more likely to be exposed to SHS at work in a smokefree community without uniform adherence to smoke-free rules. ${ }^{12}$ Among Asian-American women in California, lower-educated women were in general more likely to be exposed to SHS in workplaces and homes than higher-educated women. ${ }^{13}$

In Taiwan, the smoking rate was $33.5 \%$ for men and $4.4 \%$ for women in $2011 .^{14}$ The gender difference in smoking rates highlights the potential inequality of risk of SHS across gender. This phenomenon could be worsened by women's lower SES than men because the labour participation of Taiwanese women is lower than men $(49.97 \%$ vs $66.67 \%$ in 2011). Given a lack of evidence, large-scale studies are still needed to evaluate the effects of gender and SES differences on SHS exposure. This study examined the long-term effects of the 2009 expanded smoke-free legislation on change in SHS exposure among adult nonsmokers and whether the impact of this legislation varies across gender and socioeconomic groups.

\section{METHODS}

Data source and sample

This study used pooled cross-sectional data from the seven waves (2005-2011) of Taiwan Adult Smoking Behavior Surveys (TASBSs) conducted by 
the Health Promotion Administration (HPA) to monitor adult smoking behaviours in Taiwan. TASBSs were county-based telephone interview surveys that used probability-proportionalto-size random sampling to identify representative samples of the non-institutionalised adult population (age 18 and older) from 25 counties in Taiwan. Telephone numbers were drawn from 5 strata and categorised by the population size of 25 counties. The number of interviewees sampled per strata in each county ranged from 400 to 800 . In each sampled household, a representative adult was randomly selected. The yearly response rates were about $60 \% .{ }^{15}$ From year 2005 to 2011 , the annual sample of survey was about 16200 to 16900 (see table 1). The smoking rates dropped during the study period, from $22.75 \%$ in 2005 to $18.49 \%$ in 2011 . This study included never smokers and former smokers who reported that they had not smoked in the past month.

\section{SHS exposure}

There were two sets of SHS exposure variables: SHS in homes and SHS in workplaces. Individuals were asked 'During the past week has anyone smoked in front of you at home?' The binary variable of home SHS was 1 for 'yes' responses and 0 for 'no' responses. Other responses, such as 'unknown' or refusal to answer, were coded as missing. To define workplace SHS, we identified those non-smokers who were employed and measured SHS in workplaces for this group based on the question 'During the past week has anyone smoked in front of you at your workplace?' The binary variable of workplace SHS was coded as 1 if

Table 1 Exposure to SHS in homes or workplaces among non-smokers

\begin{tabular}{|c|c|c|c|c|c|c|c|}
\hline \multirow[b]{2}{*}{ Characteristic } & \multirow[b]{2}{*}{ Total } & \multicolumn{3}{|c|}{ SHS in homes } & \multicolumn{3}{|c|}{ SHS in workplaces (among the employed) } \\
\hline & & $\mathrm{N}$ & $\%$ & $p$ Value & $\mathrm{N}$ & $\%$ & $\mathrm{p}$ Value \\
\hline & 116596 & 96628 & 21.9 & & 43679 & 24.6 & \\
\hline Year & & & & 0.0000 & & & 0.0000 \\
\hline 2005 & 16749 & 13532 & 29.3 & & 6021 & 33.2 & \\
\hline 2006 & 16922 & 13758 & 27.4 & & 6513 & 33.3 & \\
\hline 2007 & 16588 & 13560 & 25.1 & & 6345 & 28.3 & \\
\hline 2008 & 16892 & 13959 & 21.8 & & 6387 & 26.5 & \\
\hline 2009 (the act year) & 16245 & 13709 & 15.0 & & 6163 & 13.7 & \\
\hline 2010 & 16295 & 13750 & 20.4 & & 6100 & 18.1 & \\
\hline 2011 & 16905 & 14360 & 14.6 & & 6150 & 18.2 & \\
\hline \multicolumn{8}{|l|}{ Demographic factors: } \\
\hline Gender & & & & 0.0000 & & & 0.0000 \\
\hline Female & 61898 & 59620 & 23.5 & & 26753 & 19.9 & \\
\hline Male & 54698 & 37008 & 19.5 & & 16926 & 31.2 & \\
\hline Age & & & & 0.0000 & & & 0.0000 \\
\hline $18-24$ & 13975 & 12455 & 27.7 & & 3629 & 28.6 & \\
\hline $25-34$ & 20566 & 16543 & 25.8 & & 11206 & 21.5 & \\
\hline $35-44$ & 27430 & 21822 & 23.9 & & 14094 & 24.7 & \\
\hline $45-54$ & 22704 & 18411 & 22.8 & & 9671 & 26.8 & \\
\hline $55-64$ & 13930 & 11833 & 17.6 & & 3006 & 27.9 & \\
\hline$\geq 65$ & 13750 & 11838 & 12.6 & & 443 & 22.9 & \\
\hline Missing & 4241 & 3726 & & & 1630 & & \\
\hline Education & & & & 0.0000 & & & 0.0000 \\
\hline Elementary or below & 19863 & 16981 & 19.1 & & 1823 & 29.1 & \\
\hline Junior high school & 12173 & 9053 & 27.9 & & 2847 & 35.2 & \\
\hline High school & 36818 & 28651 & 26.6 & & 13232 & 28.3 & \\
\hline Undergraduate or above & 46968 & 41269 & 16.9 & & 25467 & 16.9 & \\
\hline Missing & 774 & 674 & & & 310 & & \\
\hline Employment & & & & 0.0001 & & & \\
\hline Unemployed & 47987 & 42520 & 20.8 & & & & \\
\hline Employed & 68577 & 54083 & 22.9 & & & & \\
\hline Missing & 32 & 25 & & & & & \\
\hline Marital status & & & & 0.6920 & & & 0.0099 \\
\hline Single or widowed & 36893 & 30304 & 21.8 & & 13293 & 23.3 & \\
\hline Married & 79166 & 65877 & 22.0 & & 30170 & 25.3 & \\
\hline Missing & 537 & 447 & & & 216 & & \\
\hline Monthly income & & & & 0.0000 & & & 0.0000 \\
\hline$\leq \mathrm{NT} \$ 20000$ & 20805 & 17297 & 19.2 & & 2598 & 26.1 & \\
\hline NT\$20 000-NT\$40 000 & 24174 & 19708 & 25.0 & & 8672 & 27.1 & \\
\hline NT\$40 000-NT\$60 000 & 19914 & 16420 & 23.3 & & 9045 & 25.8 & \\
\hline NT\$60 000-NT\$80 000 & 11834 & 9821 & 21.6 & & 6309 & 22.0 & \\
\hline$\geq \mathrm{NT \$ 80000}$ & 6627 & 14207 & 19.5 & & 9802 & 20.0 & \\
\hline Missing & 10717 & 19175 & 21.9 & & 7253 & 25.5 & \\
\hline
\end{tabular}

$\mathrm{P}$, designed-based $\mathrm{F}$ test; SHS, secondhand smoke. 
the respondent answered 'yes' and 0 if they answered 'no'. The missing rates were $0.53 \%$ for home data and $21.33 \%$ for workplace data. Respondents who worked outdoors account for most of the missing data for SHS in workplaces.

\section{The 2009 smoke-free policy and covariates}

The impact of the 2009 smoke-free policy was measured in two ways. A dummy variable 'post year 2009' indicated the average effect of the expanded smoke-free legislation; the variable had a value of 1 if the survey was conducted in or after 2009 and 0 otherwise. Another set of three dummy year variables existed for the years 2009, 2010 and 2011; these variables had values of 1 if the survey was delivered in the relevant year and 0 otherwise. This set of individual dummy year variables was used to assess the impact of the 2009 smoke-free policy in each of the 3 years following its implementation. In the modelling, a trend variable was included to control the potential influence of a general decreasing trend in SHS exposure. The trend variable started from 1 for year 2005 to 7 for year 2011 .

Former smokers might have more family members or close friends who were current smokers compared to never smokers, so we included a dummy variable of former smoker in the model. The variable had a value of 1 if the non-smoker was a former smoker and 0 for never smoker. Socioeconomic status was measured using the respondent's education level and monthly household income. Education level was classified into elementary school or below, junior high school, high school and undergraduate or above. Monthly household income (in nominal value) was classified into bands of $<$ NT\$2 000 , NT $\$ 20000-60000, \quad$ NT\$60 000-80 000, NT\$ $\geq 80000$ and unknown. For each county, the survey data were used to calculate county-level smoking rates in each year as a county-level time-varied variable. Other sociodemographic characteristics included gender (male or female), age (18-24, 25-34, 35-44, $45-54,55-64$ and $\geq 65$ years), employment status (yes or no) and marital status (single or widowed, married).

\section{Statistical analysis}

Logistic regressions were conducted to examine whether SHS exposure in homes and SHS exposure in workplaces was associated with the 2009 smoke-free policy. The impact of the 2009 smoke-free policy was evaluated with two models: one model included a binary variable, post year 2009, which evaluated the average policy impact and the other model included three dummy year variables $(2009,2010$ and 2011) to evaluate the policy impact in each of the three years after 2009 .

To show policy impacts across different subpopulation groups, interaction terms between the binary policy variables and gender, education and income were entered into the models to examine the change in the three models with respect to gender, education level and income level. The analysis was stratified using the periods 3 years before and after the 2009 Act to examine disparities in SHS exposure among non-smokers associated with gender and socioeconomic status. All estimates were weighted to each individual's probability of being sampled. STATA/IC V.11.1 was used for data analysis.

\section{RESULTS}

From 2005 to 2011, SHS exposure in homes decreased from $29.3 \%$ to $14.6 \%$, and SHS exposure in workplaces decreased from $33.2 \%$ to $18.2 \%$ (table 1). Home SHS exposure rebounded significantly in 2010. Women had higher home SHS exposure than men (women: 23.5\%, men: 19.5\%), but men had higher workplace SHS exposure (women: 19.9\%, men: $31.2 \%)$. SHS exposure rates in non-smokers differed with education level. Non-smokers with junior or senior high school education levels had higher home SHS exposure rates than others (junior high school: 27.9\%, senior high school: $26.6 \%$ vs undergraduate or above: $16.9 \%$, elementary or below: $19.1 \%)$. In workplaces, non-smokers with an elementary school or lower education level had higher SHS exposure rates (junior high school: $35.2 \%$, elementary school: $29.1 \%$ ). Non-smokers with an education level of undergraduate or above had the lowest home and workplace SHS exposure rates (home: 16.9\%, workplace: $16.9 \%$ ). Non-smokers who were married or in de facto relationships had slightly higher home and workplace SHS exposure rates than single people.

Table 2 shows the self-reported SHS exposure in homes and workplaces by gender, education level and income level 3 years before and after 2009. The percentages of self-reported home

Table 2 SHS exposure in homes and workplaces among non-smokers by gender, education level and income level, before and after 2009, during 2006-2011

\begin{tabular}{|c|c|c|c|c|c|c|c|c|}
\hline \multirow[b]{3}{*}{ Characteristic } & \multicolumn{4}{|c|}{ Home SHS exposure } & \multicolumn{4}{|c|}{ Workplace SHS exposure (among the employed) } \\
\hline & \multicolumn{2}{|c|}{ Before 2009 (2006-2008) } & \multicolumn{2}{|c|}{ After 2009 (2009-2011) } & \multicolumn{2}{|c|}{ Before 2009 (2006-2008) } & \multicolumn{2}{|c|}{ After 2009 (2009-2011) } \\
\hline & $\mathrm{n}$ & Exposure $\%$ & n & Exposure \% & n & Exposure \% & $\mathbf{n}$ & Exposure \% \\
\hline \multicolumn{9}{|l|}{ Gender } \\
\hline Female & 26029 & 0.27 & 24933 & 0.18 & 12057 & 0.24 & 10841 & 0.12 \\
\hline Male & 15248 & 0.22 & 16886 & 0.15 & 7188 & 0.37 & 7572 & 0.23 \\
\hline \multicolumn{9}{|l|}{ Education } \\
\hline Undergraduate or above & 17569 & 0.18 & 18259 & 0.14 & 11088 & 0.36 & 11024 & 0.21 \\
\hline High school & 16260 & 0.30 & 16060 & 0.21 & 7162 & 0.37 & 6589 & 0.20 \\
\hline Elementary school or below & 7110 & 0.23 & 7313 & 0.13 & 830 & 0.19 & 726 & 0.11 \\
\hline \multicolumn{9}{|l|}{ Monthly income } \\
\hline$\geq \mathrm{NT} \$ 80000$ & 6192 & 0.22 & 6378 & 0.15 & 4382 & 0.23 & 4255 & 0.14 \\
\hline NT\$60 000-NT\$80 000 & 4173 & 0.24 & 4465 & 0.18 & 2755 & 0.26 & 2780 & 0.14 \\
\hline NT\$20 000-NT\$60 000 & 14939 & 0.27 & 16828 & 0.19 & 7432 & 0.33 & 8163 & 0.18 \\
\hline$\leq \mathrm{NT} \$ 20000$ & 6679 & 0.23 & 8376 & 0.15 & 1012 & 0.33 & 1318 & 0.19 \\
\hline Missing & 9294 & 0.24 & 5772 & 0.14 & 3664 & 0.28 & 1897 & 0.16 \\
\hline
\end{tabular}


SHS exposure before 2009 were higher among women (27\% vs $22 \%$ for men), those with a high school education level (30\% vs $18 \%$ of undergraduate or above and $23 \%$ of elementary school or below) and those with income of NT\$20 000-NT\$60 000 ( $27 \%$ vs $22 \%$ to $24 \%$ of the other income groups). The impact of the 2009 smoke-free policy in reducing home SHS exposure was greatest among women $(-9 \%)$, those with an elementary school education or lower $(-10 \%)$ and respondents with missing income information (-10\%). The workplace SHS exposure before 2009 was higher among men (37\% vs 24\% for women), those with a high school education or below (36\% to $37 \%$ vs $19 \%$ for elementary school or below) and those with monthly income below NT\$60 000 (33\% vs 23\% to 26\% for income above NT\$60 000). After 2009 the percentage of workplace SHS exposure reduced by $10 \%$ to $16 \%$ for most groups, with the exception of respondents in the highest education level group, who reported a reduction of just $8 \%$.

Table 3 analyses the SHS exposure in homes and workplaces using two models. Model 1 included a policy variable, 'post year 2009', which covered the period 2009-2011 to analyse the average impact of the 2009 smoke-free policy on reducing SHS exposure. Model 2 replaced the dummy policy variable with three dummy year variables: 2009, 2010 and 2011, to estimate the individual effect for each year. Model 1 of SHS exposure in homes showed the SHS exposure in homes decreased by $11 \%$ after 2009 (OR $=0.89,95 \%$ CI 0.81 to 0.98$)$. Former smokers were more likely to be exposed to home SHS than never smokers $(\mathrm{OR}=1.64,95 \% \mathrm{CI} 1.49$ to 1.81$)$. Non-smoking men were less likely than women to be exposed to SHS in homes $(\mathrm{OR}=0.75,95 \%$ CI 0.7 to 0.79$)$. Higher odds of SHS exposure in homes were significantly associated with lower education and income level. Model 2 showed that the odds of non-smokers being exposed to SHS in homes reduced significantly in 2009 $(\mathrm{OR}=0.76,95 \%$ CI 0.68 to 0.84$)$, but increased in 2010 $(\mathrm{OR}=1.28,95 \%$ CI 1.12 to 1.46$)$ and by 2011 had returned to pre-2009 levels (OR $=0.97,95 \%$ CI 0.82 to 1.14$)$. SHS exposure in homes showed a decreasing trend for SHS exposure in homes $(\mathrm{OR}=0.91,95 \% \mathrm{CI} 0.89$ to 0.93$)$. These results suggest

Table 3 Logistic regressions on exposure to SHS among non-smokers in Taiwan, 2005-2011

\begin{tabular}{|c|c|c|c|c|c|c|c|c|}
\hline \multirow[b]{3}{*}{ Characteristic } & \multicolumn{4}{|c|}{ Exposure of SHS in homes } & \multicolumn{4}{|c|}{ Exposure of SHS in workplaces (among the employed) } \\
\hline & \multicolumn{2}{|c|}{ Model 1} & \multicolumn{2}{|c|}{ Model 2} & \multicolumn{2}{|l|}{ Model 1} & \multicolumn{2}{|l|}{ Model 2} \\
\hline & OR & $95 \% \mathrm{Cl}$ & OR & $95 \% \mathrm{Cl}$ & OR & $95 \% \mathrm{Cl}$ & OR & $95 \% \mathrm{Cl}$ \\
\hline Post year 2009 (reference: year 2005-2008) & 0.89 & (0.81 to 0.98$)$ & & & 0.57 & (0.47 to 0.69$)$ & & \\
\hline \multicolumn{9}{|l|}{ Years } \\
\hline 2009 & & & 0.76 & (0.68 to 0.84$)$ & & & 0.49 & (0.39 to 0.62$)$ \\
\hline 2010 & & & 1.28 & (1.13 to 1.46$)$ & & & 0.79 & (0.66 to 0.95$)$ \\
\hline 2011 & & & 0.98 & (0.83 to 1.15$)$ & & & 0.90 & (0.70 to 1.16$)$ \\
\hline \multicolumn{9}{|l|}{ Former smoking } \\
\hline \multicolumn{9}{|l|}{ Reference: never smokers } \\
\hline Former smokers & 1.64 & (1.49 to 1.81$)$ & 1.65 & (1.50 to 1.81$)$ & 1.48 & (1.34 to 1.63$)$ & 1.49 & (1.35 to 1.65$)$ \\
\hline \multicolumn{9}{|l|}{ Gender } \\
\hline \multicolumn{9}{|l|}{ Reference: female } \\
\hline Male & 0.75 & (0.71 to 0.79$)$ & 0.75 & (0.71 to 0.79$)$ & 1.94 & (1.78 to 2.12$)$ & 1.94 & (1.78 to 2.12 ) \\
\hline \multicolumn{9}{|l|}{ Age } \\
\hline \multicolumn{9}{|l|}{ Reference: 18-24 } \\
\hline $25-34$ & 0.78 & (0.71 to 0.86$)$ & 0.79 & (0.72 to 0.86$)$ & 0.75 & (0.67 to 0.83 ) & 0.75 & (0.67 to 0.85$)$ \\
\hline $35-44$ & 0.57 & (0.52 to 0.62 ) & 0.57 & (0.52 to 0.62 ) & 0.76 & (0.68 to 0.85 ) & 0.77 & (0.69 to 0.86$)$ \\
\hline $45-54$ & 0.46 & (0.41 to 0.53 ) & 0.47 & (0.41 to 0.53 ) & 0.70 & (0.61 to 0.80 ) & 0.71 & (0.62 to 0.80$)$ \\
\hline $55-64$ & 0.32 & (0.28 to 0.36$)$ & 0.31 & (0.28 to 0.36$)$ & 0.65 & (0.52 to 0.81$)$ & 0.65 & (0.52 to 0.81 ) \\
\hline$\geq 65$ & 0.21 & (0.18 to 0.24 ) & 0.21 & (0.18 to 0.24 ) & 0.41 & (0.31 to 0.53$)$ & 0.41 & (0.31 to 0.54$)$ \\
\hline \multicolumn{9}{|l|}{ Education } \\
\hline \multicolumn{9}{|l|}{ Reference: undergraduate or above } \\
\hline High school & 1.93 & (1.78 to 2.10$)$ & 1.94 & (1.79 to 2.10$)$ & 2.15 & (1.97 to 2.33$)$ & 2.14 & (1.97 to 2.33 ) \\
\hline Elementary or below & 2.27 & (2.02 to 2.55 ) & 2.28 & (2.03 to 2.57 ) & 2.42 & (2.04 to 2.88 ) & 2.42 & (2.04 to 2.87 ) \\
\hline \multicolumn{9}{|l|}{ Employment } \\
\hline \multicolumn{9}{|l|}{ Reference: unemployed } \\
\hline Employed & 1.03 & (0.98 to 1.09 ) & 1.03 & (0.98 to 1.09 ) & (omitted) & & (omitted) & \\
\hline \multicolumn{9}{|l|}{ Marital status } \\
\hline \multicolumn{9}{|l|}{ Reference: single or widowed } \\
\hline Married & 1.19 & (1.10 to 1.29$)$ & 1.19 & (1.10 to 1.29$)$ & 1.12 & (1.05 to 1.21$)$ & 1.13 & (1.05 to 1.21$)$ \\
\hline \multicolumn{9}{|l|}{ Monthly income } \\
\hline \multicolumn{9}{|l|}{ Reference: $\geq N T \$ 80000$} \\
\hline NT\$60 000-NT\$80 000 & 1.06 & (0.97 to 1.15$)$ & 1.06 & (0.97 to 1.15$)$ & 1.08 & (0.94 to 1.24$)$ & 1.08 & (0.94 to 1.23 ) \\
\hline NT\$20 000-NT\$60 000 & 1.14 & (1.07 to 1.22$)$ & 1.14 & (1.06 to 1.22$)$ & 1.23 & (1.08 to 1.40$)$ & 1.24 & (1.09 to 1.41$)$ \\
\hline$\leq \mathrm{NT} \$ 20000$ & 1.12 & (1.02 to 1.24$)$ & 1.12 & (1.02 to 1.24$)$ & 1.21 & (1.00 to 1.47 ) & 1.23 & (1.02 to 1.50$)$ \\
\hline Missing & 1.00 & (0.92 to 1.08 ) & 0.99 & (0.92 to 1.07 ) & 1.05 & (0.92 to 1.20 ) & 1.05 & (0.92 to 1.20$)$ \\
\hline City smoke rate (\%) & 1.04 & (1.02 to 1.06$)$ & 1.04 & (1.02 to 1.06$)$ & 1.01 & (0.99 to 1.03 ) & 1.01 & (0.99 to 1.03 ) \\
\hline Trend & 0.91 & (0.89 to 0.93 ) & 0.88 & (0.86 to 0.91$)$ & 0.93 & (0.90 to 0.97$)$ & 0.87 & (0.84 to 0.91$)$ \\
\hline
\end{tabular}

SHS, secondhand smoke. 
that the 2009 smoke-free policy had an immediate impact on SHS, but the impact on SHS in homes was not lasting.

Model 1 of SHS exposure in workplaces showed that after 2009, SHS exposure in workplaces significantly decreased by $43 \%(\mathrm{OR}=0.57,95 \% \mathrm{CI} 0.47$ to 0.68$)$. In workplaces, former smokers were more likely to be exposed to SHS $(\mathrm{OR}=1.48$, 95\% CI 1.34 to 1.63$)$. Men were more likely to be exposed to workplace SHS than women $(\mathrm{OR}=1.94,95 \%$ CI 1.78 to 2.12$)$. Higher odds of workplace SHS exposure were significantly associated with the two lowest education levels: high school $(\mathrm{OR}=2.14,95 \% \mathrm{CI} 1.97$ to 2.33$)$ and elementary school $(\mathrm{OR}=2.42$, 95\% CI 2.04 to 2.88). Model 2 showed that SHS exposure in workplaces significantly decreased in 2009 $(\mathrm{OR}=0.49,95 \%$ CI 0.39 to 0.61$)$ and $2010(\mathrm{OR}=0.78,95 \%$ CI 0.65 to 0.93$)$ but not in 2011 (OR $=0.90,95 \%$ CI 0.70 to 1.16). The odds of SHS exposure in workplaces were significantly higher among the two lowest income groups $(\mathrm{OR}=1.24$ and 1.23). Reporting of SHS exposure in workplaces decreased over the study period $(\mathrm{OR}=0.87,95 \% \mathrm{CI} 0.84$ to 0.91$)$.

Table 4 showed logistic regressions on SHS exposure concerning the interaction effect of the 2009 smoke-free policy. There were three models for home and workplace SHS exposure, each of which added an interaction with the 2009 policy implementation to the model 1 in table 3 . The table shows the estimated parameters for the 2009 policy implementation, sociodemographic factors (gender, education and income), and the interaction between the 2009 smoke-free policy and sociodemographic factors. The interaction terms were to examine the change in inequality of SHS exposure in homes and workplaces after the 2009 smoke-free policy. The results for SHS exposure in homes with the interaction term between gender and the 2009 smoke-free policy suggested that non-smoking men had a lower risk than women of SHS exposure in homes $(\mathrm{OR}=0.79$, 95\% CI 0.73 to 0.86$)$. The 2009 smoke-free policy reduced the reporting of SHS exposure in homes by $33 \%(\mathrm{OR}=0.67,95 \% \mathrm{CI} 0.61$ to 0.74$)$, and the interaction coefficient was insignificantly greater than $1(\mathrm{OR}=1.10,95 \%$ CI 0.98 to 1.23 ). This suggested that the smoke-free policy had a limited impact in reducing gender differences in home SHS exposure. With regards to education levels, less educated non-smokers had significantly higher odds of home SHS exposure. Nevertheless, the interaction ORs $(\mathrm{OR}=0.87$ and $0.71)$ were $<1$ and lower than for the respondents with higher education level. This suggested that the smoke-free policy had a greater effect on reducing SHS in homes among less-educated non-smokers, and that inequalities in SHS exposure in homes with respect to education levels have decreased since 2009. The insignificant ORs of the interaction term for income showed the impact of the 2009 smoke-free policy in reducing SHS in homes did not differ across income levels, and differences in home SHS exposure among income groups were not reduced after 2009.

Table 4 Logistic regression on SHS exposure with interaction with the 2009 smoke-free policy and gender/socioeconomic factors, 2006-2011 *

\begin{tabular}{|c|c|c|c|c|}
\hline \multirow[b]{2}{*}{ Factor } & \multicolumn{2}{|c|}{ SHS exposure in homes } & \multicolumn{2}{|c|}{ SHS exposure in workplaces } \\
\hline & OR & $95 \% \mathrm{Cl}$ & OR & $95 \% \mathrm{Cl}$ \\
\hline \multicolumn{5}{|l|}{ Model 1: interaction with gender } \\
\hline \multicolumn{5}{|l|}{ The 2009 policy (reference: $2006-2008$ ) } \\
\hline Year 2009-2011 & 0.67 & 0.61 to 0.74 & 0.45 & 0.37 to 0.54 \\
\hline \multicolumn{5}{|l|}{ Gender (reference: female) } \\
\hline Male & 0.79 & 0.73 to 0.86 & 2.02 & 1.80 to 2.27 \\
\hline \multicolumn{5}{|c|}{ Gender $\times$ the 2009 policy interaction (reference: female $\times$ year $(2009-2011)$ ) } \\
\hline Male $\times($ year 2009-2011) & 1.10 & 0.98 to 1.23 & 1.13 & 0.92 to 1.39 \\
\hline \multicolumn{5}{|l|}{ Model 2: interaction with education } \\
\hline \multicolumn{5}{|l|}{ The 2009 policy (reference: $2006-2008$ ) } \\
\hline Year 2009-2011 & 0.82 & 0.75 to 0.89 & 0.53 & 0.46 to 0.60 \\
\hline \multicolumn{5}{|l|}{ Education (reference: undergraduate or above) } \\
\hline High school & 2.03 & 1.87 to 2.20 & 2.40 & 2.15 to 2.68 \\
\hline Elementary school or below & 2.51 & 2.19 to 2.88 & 2.85 & 2.32 to 3.50 \\
\hline \multicolumn{5}{|c|}{ Education $\times$ the 2009 policy interaction (reference: undergraduate or above $\times$ (year 2009-2011)) } \\
\hline High school × (year 2009-2011) & 0.87 & 0.79 to 0.96 & 0.84 & 0.71 to 1.01 \\
\hline Elementary school or below $\times$ (year 2009-2011) & 0.71 & 0.60 to 0.85 & 0.89 & 0.65 to 1.22 \\
\hline \multicolumn{5}{|l|}{ Model 3: interaction with income } \\
\hline \multicolumn{5}{|l|}{ The 2009 policy (reference: $2006-2008$ ) } \\
\hline Year 2009-2011 & 0.71 & 0.62 to 0.81 & 0.52 & 0.42 to 0.65 \\
\hline \multicolumn{5}{|l|}{ Monthly income (reference: $\geq N T \$ 80000$ ) } \\
\hline NT\$60 000-NT\$80 000 & 1.02 & 0.91 to 1.14 & 1.09 & 0.88 to 1.35 \\
\hline NT\$20 000-NT\$60 000 & 1.12 & 1.04 to 1.22 & 1.27 & 1.06 to 1.53 \\
\hline$\leq \mathrm{NT} \$ 20000$ & 1.20 & 1.05 to 1.36 & 1.21 & 0.91 to 1.61 \\
\hline Missing & 1.07 & 0.96 to 1.18 & 1.06 & 0.89 to 1.26 \\
\hline \multicolumn{5}{|c|}{ Income $\times$ the 2009 policy interaction (reference: $\geq$ NT\$80 $000 \times$ year 2006-2008) } \\
\hline NT\$60 000-NT\$80 $000 \times($ year 2009-2011) & 1.11 & 0.92 to 1.34 & 0.90 & 0.67 to 1.20 \\
\hline NT\$20 000-NT\$60 $000 \times$ (year 2009-2011) & 1.03 & 0.89 to 1.19 & 0.88 & 0.70 to 1.10 \\
\hline$\leq \mathrm{NT} \$ 20000 \times($ year 2009-2011) & 0.92 & 0.76 to 1.12 & 0.95 & 0.69 to 1.32 \\
\hline Missing $\times($ year 2009-2011) & 0.84 & 0.71 to 1.01 & 0.92 & 0.73 to 1.17 \\
\hline
\end{tabular}

* Other covariates included age, gender, employment, marital status, county smoking rate and trend.

SHS, secondhand smoke. 
Table 5 Statistics on inspections and sanctions on smoke-free policy, 2008-2011 1417

\begin{tabular}{cccccccc}
\hline & \multicolumn{2}{l}{ Smoking in no-smoking areas } & & \multicolumn{3}{l}{ Not posit no-smoking sign } \\
\cline { 2 - 3 } Year & Inspections & Sanctions & $\%$ & & Inspections & Sanctions & $\%$ \\
\hline 2008 & 148604 & 63 & 0.04 & & 223060 & 264 & 0.12 \\
2009 & 648501 & 3648 & 0.56 & 683283 & 357 & 0.05 \\
2010 & 440577 & 4584 & 1.04 & 435993 & 468 & 0.11 \\
2011 & 421128 & 5591 & 1.33 & 412127 & 772 & 0.19 \\
\hline
\end{tabular}

Non-smoking working men had greater odds of SHS exposure in workplaces $(\mathrm{OR}=2.02,95 \% \mathrm{CI} 1.80$ to 2.27$)$ compared with women. The insignificant interaction $\mathrm{OR}$ showed no gender differences in the impact of the 2009 smoke-free policy on reducing SHS in workplaces. This implied limited effects of reduced inequality of workplace SHS exposure between men and women. Non-smokers with lower education level had significantly higher odds of workplace SHS $(\mathrm{OR}=2.4$ and 2.85). The insignificant interaction terms $(\mathrm{OR}=0.84$ and 0.89$)$ suggested the 2009 policy did not reduce existing inequalities in workplace SHS exposure associated with education level. The odds of workplace SHS exposure were higher in the NT \$20 000-NT\$60 000 income group than the highest income group. The interaction terms suggested that the 2009 smokefree policy did not reduce income differences in workplace SHS exposure.

\section{DISCUSSION}

The immediate and long-term effects of the 2009 smoke-free policy

Among the three main policies in the 2009 Act, smoke-free legislation was the policy that targeted a reduction in SHS exposure. This study provides evidence that the smoke-free policy in the 2009 Act significantly reduced SHS exposure in homes and workplaces, independent of the existing trend of decreasing SHS exposure. SHS exposure in homes 2 years after $2009(14.6 \%)$ was lower than in Italy 5 years after it implemented a similar smoking ban (17.9\%). ${ }^{16}$ The reporting of SHS exposure in workplaces decreased by $51 \%$ in the year the act was implemented (from regression results), but this decrease reduced to only $22 \%$ in the second year of implementation, and by the third year there was no significant effect.

The reason for increase of SHS exposure from 2009 to 2010 (from $15 \%$ to $20.4 \%$ in homes; from $13.7 \%$ to $18.1 \%$ in workplaces) is unknown. One possibility is that as an environment becomes smoke-free, social norms surrounding smoking may change. People may notice active smoking more in the presence of a smoking ban as opposed to times when smoking was allowed everywhere. Therefore, the results in 2010, which showed a relatively dramatic increase in reported SHS exposures, may be an artefact due to the changing social norms and smoke-free environment from the previous year.

Another possibility is decreasing compliance with smoke-free policy. In January 2004, the HPA established the Tobacco Hazards Prevention Act Inspections and Punishments Reporting and Case Management Information System. It is clear that the number of inspections increased significantly in 2009 when the smoke-free policy was strengthened, with a sanction rate of $0.56 \%$. In 2011, the number of inspections decreased to 421128 with a sanction rate of $1.33 \%$. Similarly, in 2009 , among 683283 no-smoking areas inspected, $0.05 \%$ did not posit the no smoking sign required. In 2011, the sanction rate increased to $0.19 \% .{ }^{14} 17$ The evidence implied that the longterm effect of the 2009 smoke-free policy should be monitored and its re-inforcement be strictly implemented and advocacy of the smoke-free home might be the next step of smoke-free policy. Nevertheless, the change in SHS exposure should not be considered the consequence of a single policy, namely the prohibition of smoking indoors. Other tobacco control policies designed to reduce smoking, including cigarette taxes or graphic warnings on cigarette packs, might also have indirect influence on reductions in SHS exposure.

In 2006 the tax on cigarettes was increased. This tax increase might have reduced smoking rates and hence the odds of SHS exposure. To control for the potential indirect effect of the 2006 cigarette tax increase on SHS exposure, city-level timevaried smoking rates were included in the models. The results showed that the aggregate city smoking rates influenced the odds of SHS exposure and thus implied that the odds of SHS exposure were not influenced only by smoke-free policy enforcement but were also affected by other tobacco control policies intended to reduce smoking. Thus, the rebound of SHS in homes and the lack of a significant policy effect in reducing SHS in workplaces in 2011 were independent of city smoking rates and other factors. This evidence highlights the urgent need to strengthen the smoke-free policy owing to its weakening effect in reducing smoking and prohibiting smoking indoors.

\section{Gender differences}

Non-smoking women were more likely to be exposed to home SHS, while non-smoking men were more likely to be exposed to workplace SHS. The gender difference in workplace SHS exposure mainly results from the difference of occupation type across gender; $40.88 \%$ of working men were in more manufacturing or 'blue-collar' jobs, higher than the $19.10 \%$ observed for women. ${ }^{18}$ Following the 2009 smoke-free policy, SHS exposure in workplaces was reduced among non-smoking women and men, but the changes during the two periods were insufficient to significantly reduce the persistent gender inequalities in workplace SHS exposure.

After 2009, SHS exposure in homes was reduced among nonsmoking women and men. However, the changes during the two periods were insufficient to significantly reduce the persistent gender inequalities in home and workplace SHS exposure. The gender differences in home SHS exposure provide insights into Taiwanese smoking culture. In Taiwan, the general prevalence of smoking was higher among men (33.5\%) than women (4.4\%) in 2011. ${ }^{17}$ This gender imbalance in smoking culture reduces the risk of home SHS exposure for married men because their wives are less likely to smoke. In contrast, for women, changes in SHS risk associated with marriage depend on the smoking habits of male family members, from fathers and/or brothers to husbands and/or sons. Gender differences in smoking thus impose a heavier external cost of SHS exposure on women.

\section{Socioeconomic differences}

The odds of SHS exposure in homes and workplaces were much higher among non-smokers with lower education levels than those with undergraduate degrees or above. The smokefree policy in the 2009 Act significantly reduced the exposure of SHS across all educational groups. Differences in home SHS exposure with education level reduced significantly after 2009, but differences in workplace SHS exposure persisted mostly. This policy effect on SHS in homes differed from study results 
on smoke-free legislation in Wales, where post-legislation reductions in SHS exposure were limited to children from higher SES households. ${ }^{19}$ The inequality in SHS across income levels resembled that for education levels. Non-smokers in low-income families were more likely to be exposed to SHS in homes and workplaces. The inequality in SHS exposure in homes and in workplaces across income groups persisted after 2009. It has been argued that laws to make workplaces and public places smoke-free will induce smokers to smoke more at home to satisfy their addiction and compensate for smoking restrictions elsewhere. ${ }^{20}$ Alternatively, another argument runs that such laws might encourage people to restrict their smoking at home. ${ }^{7}$ This study found no significant evidence of a displacement effect since self-reported home and workplace SHS exposure were both reduced after 2009. However, SHS exposure in homes increased significantly 1 year later, which implies that further investigation of the long-term effect of the smoke-free policy is needed. In fact, strong clean indoor air laws are more effective in homes without smokers than those with smokers. ${ }^{4}$ A more appropriate way to test the displacement effect would be needed to examine whether smokers became more likely to smoke in homes after 2009. Alternatively, future studies could examine the social diffusion hypothesis by examining whether households with smoking family members started to restrict smoking indoors after 2009. The increase in SHS exposure in 2010 demonstrates the need for further analysis of the long-term effects of the smoke-free policy.

In our study, there was a potential issue of collinearity between education and income level. Among the subjects in lowest income group, $69.7 \%$ had the education degree of elementary school or bellow and $0.05 \%$ had degree of undergraduate or above. Among the subjects in the highest income group, $0.07 \%$ had the education degree of elementary school or bellow and $60.2 \%$ had degree of undergraduate or above. The designbased F test was significant. Sensitivity analysis on the models was conducted by dropping one of these two SES variables each time and compared the results with the original model. The results showed that the policy effect was unaffected when dropping either of the two variables. Estimates on education effect were unaffected when income variables were removed. However, when we dropped the educational variable, estimate of the second highest income group became significant. Most of the magnitudes of estimates were close to the coefficients in the original models.

\section{Study limitations}

The secondary data used in this study came from telephone interview surveys that were subject to the limitations of recall and measurement bias typical of self-reported information. However, the repose rate of the telephone survey was only $60 \%$, and this might cause a potential selection bias. Further, the internal validity of the definition of SHS exposure is imperfect. The question 'has anyone smoked in front of you at home/ at your workplace?' does not necessarily capture SHS exposure in homes or workplaces. In fact, the question used to assess the workplace SHS exposure might be invalid because it included the SHS exposure in outdoor areas. The telephone interview surveys did contain another question dealing with this issue: do your family members smoke at home? Analysis of answers to this question yielded similar results to the findings of the current study. However, this question alone also cannot accurately capture the exposure of SHS at home. Moreover, this question was not included in the surveys for 2009 and 2011, making analysis of the policy impact on SHS in homes difficult.
Approximately $25 \%$ of respondents provided no income data. This income group had lower likelihood of exposure to SHS than other groups. This group also had a unique age distribution. This group contained higher proportions of respondents in the youngest and oldest age groups $(24.5 \%$ and $16.9 \%)$ than did the known income groups $(1.9 \%$ and $7.1 \%)$. This unknown income group also had a higher proportion of respondents with undergraduate or higher education level than the other income groups. These two characteristics partially explain the lower odds of SHS exposure. This study was unable to include other potential proxy variables for controlling the effects of increased cigarette taxes, media campaigns and graphic warning labels.

\section{CONCLUSIONS}

The smoke-free policy of the 2009 Act significantly reduced SHS exposure in homes and workplaces, but was followed by a rebound of home SHS exposure since 2010. Significant differences were observed between SHS exposure in homes and workplaces across gender and education level, and these differences persisted after 2009. Future policies should strengthen implementation of the smoke-free policy, and should specifically target those women who are subject to a higher risk of SHS in homes and those men who are subject to higher risk of SHS in workplaces.

\section{What this paper adds}

- This is a 3-year evaluation of reduction in secondhand smoke (SHS) exposure among non-smokers in workplaces and homes as a result of the enforcement of a national smoke-free law in year 2009.

- We examined the relationship between SHS exposure and socioeconomic status. We found a strong inverse association between education level and SHS exposure.

- Our study demonstrated the effect of smoke-free laws on reducing the differences in SHS exposure across education levels.

Contributors All authors had full access to all the data in the study and take responsibility for the integrity of the data analysis. All authors contributed to drafts and approved of the final version of the paper. Y-WT and S-TC conceived the study and were in charge of major work of manuscript writing. L-CC undertook the data analysis and completed the parts of method and result in the manuscript. $\mathrm{H}-\mathrm{YS}$ and T-wH led the study design and data analysis and revised the manuscript.

Funding National Yang-Ming University received research funding from the Health Promotion Administration for the project titled International Collaborative Research on Tobacco Control Polices in Taiwan. No financial disclosures were reported by the authors of this paper. CCY10009, CCY10009-1, CCY10009-102.

\section{Competing interests None.}

Ethics approval This is a secondary analysis of data collected by the Health Promotion Administration and provided as a de-identified data set.

Provenance and peer review Not commissioned; externally peer reviewed.

\section{REFERENCES}

1 Chang FC, Chung C-H, Chuang Y-C, et al. Effect of media campaigns and smoke-free ordinance on public awareness and secondhand smoke exposure in Taiwan. J Health Commun 2011;16:343-58

2 López MJ, Nebot M, Schiaffino A, et al. Two-year impact of the Spanish smoking law on exposure to secondhand smoke: evidence of the failure of the 'Spanish model'. Tob Control 2012;21:407-11. 
3 Yao T, Lee AH, Mao Z. Potential unintended consequences of smoke-free policies in public places on pregnant women in China. Am J Prev Med 2009;37:S159-64.

4 Haw SJ, Gruer L. Changes in exposure of adult non-smokers to secondhand smoke after implementation of smoke-free legislation in Scotland: national cross sectional survey. BMJ 2007;335:549.

5 Erazo $M$, Iglesias $V$, Droppelmann A, et al. Secondhand tobacco smoke in bars and restaurants in Santiago, Chile: evaluation of partial smoking ban legislation in public places. Tob Control 2010;19:469-74.

6 Mons U, Nagelhout GE, Allwright S, et al. Impact of national smoke-free legislation on home smoking bans: findings from the International Tobacco Control Policy Evaluation Project Europe Surveys. Tob Control 2013;22:e2-9.

7 Cheng KW, Glantz SA, Lightwood JM. Association between smokefree laws and voluntary smokefree-home rules. Am J Prev Med 2011;41:566-72.

8 Akhtar PC, Currie DB, Currie CE, et al. Changes in child exposure to environmental tobacco smoke (CHETS) study after implementation of smoke-free legislation in Scotland: national cross sectional survey. BMJ 2007;335:545.

9 Jarvis MJ, Sims M, Gilmore A, et al. Impact of smoke-free legislation on children's exposure to secondhand smoke: cotinine data from the Health Survey for England. Tob Control 2012;21:18-23.

10 Hahn EJ. Smokefree legislation: a review of health and economic outcomes research. Am J Prev Med 2010;39:S66-76.

11 Bell $\mathrm{K}$, et al. Location restrictions on smoking: assessing their differential impacts and consequences in the workplace. Can J Public Health 2009;100:46-50.
12 Moore RS, Annechino RM, Lee JP. Unintended consequences of smoke-free bar policies for low-SES women in three California counties. Am J Prev Med 2009;37: S138-43.

13 Tong EK, Tang H, Tsoh J, et al. Smoke-free policies among Asian-American women: comparisons by education status. Am J Prev Med 2009;37:S144-50.

14 Bureau of Health Promotion. Taiwan tobacco control 2012 annual report. Taipei: Bureau of Health Promotion, Department of Health, 2012.

15 Chang F, Hu T-w, Lo S-y, et al. Quit smoking advice from health professionals in Taiwan: the role of funding policy and smoker socioeconomic status. Tob Control 2010;19:44-9.

16 Martínez-Sánchez JM, Gallus S, Zuccaro P, et al. Exposure to secondhand smoke in Italian non-smokers 5 years after the Italian smoking ban. Eur J Public Health 2012:22:707-12.

17 Bureau of Health Promotion. Taiwan tobacco control 2011 annual report. Taipei: Bureau of Health Promotion, Department of Health, 2011.

18 The Directorate-General of Budget, Accounting and Statistics, Exercutive Yuan, R.O.C. (Taiwan). Statistics of Labor Force. 2009.

19 Moore GF, Holliday JC, Moore LAR. Socioeconomic patterning in changes in child exposure to secondhand smoke after implementation of smoke-free legislation in Wales. Nicotine Tob Res 2011;13:903-10.

20 Lock K, Adams E, Pilkington P, et al. Evaluating social and behavioural impacts of English smoke-free legislation in different ethnic and age groups: implications for reducing smoking-related health inequalities. Tob Control 2010;19:391-7. 